\title{
Syntheses of Coordination Compounds of ( \pm )-2-Amino-3-(4-Hydroxyphenyl)Propionic Acid, Mixed Ligand Complexes and Their Biological Activities
}

\author{
Temitayo 0. Aiyelabola*, Ezekiel O. Akinkunmi, Raphael Akinade \\ Department of Chemistry, Obafemi Awolowo University, Ile-Ife, Osun State, Nigeria \\ Email: *taiyelabola@gmail.com
}

How to cite this paper: Aiyelabola, T.O., Akinkunmi, E.O. and Akinade, R. (2020) Syntheses of Coordination Compounds of ( \pm )-2-Amino-3-(4-Hydroxyphenyl)Propionic Acid, Mixed Ligand Complexes and Their Biological Activities. Advances in Biological Chemistry, 10, 25-42.

https://doi.org/10.4236/abc.2020.102003

Received: January 3, 2020

Accepted: March 16, 2020

Published: March 19, 2020

Copyright $\odot 2020$ by author(s) and Scientific Research Publishing Inc. This work is licensed under the Creative Commons Attribution International License (CC BY 4.0).

http://creativecommons.org/licenses/by/4.0/

\begin{abstract}
Coordination compounds of ( \pm )-2-amino-3-(4-hydroxyphenyl)propionic acid and their mixed ligand complexes with 1,10-phenantroline were synthesized, characterized using electronic and infrared spectral analyses and magnetic susceptibility. The compounds were evaluated for antimicrobial and antioxidant activities. Four different assays were applied for evaluating antioxidant capacity of the compounds. The results obtained indicated a diametric square planar geometry for both cobalt ( \pm )-2-amino-3-(4-hydroxyphenyl)propionic acid complex and its mixed ligand complex. It was suggested that for the binary cobalt(II) complex, the phenolic substituent coordinated with neighbouring central metal ions. However, for the ternary cobalt(II) complex it was suggested it was deprotonated. Octahedral geometry was proposed for both copper complexes. Square planar geometry was indicated for the nickel ( \pm )-2-amino-3-(4-hydroxyphenyl)propionic acid complex and a mixture of square planar and octahedral geometry for the nickel mixed ligand complex. The cobalt mixed ligand complex elicited the highest activity for all the antioxidant assays. In most cases the binary complexes exhibited better antimicrobial activities relative to their ternary counterparts.
\end{abstract}

\section{Keywords}

Coordination Compounds, Antimicrobial Agent, Antioxidant, Mixed Ligand, 1,10-Phenantroline

\section{Introduction}

A key part of research in medicinal chemistry involves the finding of compounds 
which may serve as lead for therapeutic use. These include coordination compounds, because of their unique properties and broad range of applications; including anti-microbial, -cancer and -oxidant [1] [2] [3] [4]. In combination with a variety of ligands transition metals, form mixed ligand complexes. Some of these have been shown to exhibit anti-biotic and-cancer activities [5] [6]. In this regard, extensive applications have been found for 1,10-phenanthroline, a bidentate ligand that forms very stable chelates with many first-row transition metals [7]. The ideally placed nitrogen atoms, of this molecule, along with its rigid planar structure, hydrophobic, electron-poor heteroaromatic, and $\pi$-acidic properties, cooperatively make 1,10-phenanthroline a classic chelating ligand, for mixed ligand complexes [7].

Various metabolic processes in living systems and environmental stresses generate various reactive species. These include free radicals and mainly reactive oxygen species (ROS) [8] [9] [10] [11]. Increased level of ROS can damage structure of biomolecules and modify their functions and lead to cellular dysfunction and possibly cell death. The cumulative effect of increased ROS can therefore increase oxidative stress which may be manifested in the form of a variety of health problems such as cancer, age related disease and cardiovascular diseases [8] [9] [10] [11]. As a result of pathologies associated with the attack of free radicals, there is a general need for antioxidant compounds. These compounds are capable of delaying or inhibiting the oxidation processes which occur under the influence of atmospheric oxygen or reactive oxygen species [12] [13] [14]. As such in some cases they are considered to be involved in the defense mechanism against pathogens resulting from such activities. In cases in which endogenous factors are unable to ensure the control and complete protection of an organism against the reactive oxygen species, the need for exogenous antioxidant compounds arises. This may be obtained as nutritional supplements, pharmaceutical products and some fruits. A class of compound with potential antioxidant activity is the phenols and polyphenols [12] [13] [14].

Previous studies have indicated that some cancer cells are related to some microorganisms [15] [16]. Additionally, reports have shown that high levels of reactive oxygen species have been detected in most cancers, where they promote tumor development and progression [16] [17]. One of the principal public health problems of this century is the emergence of the resistant microorganisms, increasing the numbers of infections caused by microorganisms no longer susceptible to the common medicines used to treat them [17] [18]. Studies of potential lead compounds with antimicrobial activity with antimicrobial and antioxidant activities having minimal side effects are considered needful. Therefore it was considered to synthesize coordination compound of ( \pm )-2-amino-3-(4-hydroxyphenyl)propionic acid (Figure 1), its mixed ligand complexes with 1,10-phenantroline (Figure 2) and to investigate the antimicrobial and antioxidant activities of these compounds. The compounds were characterized using infrared, electronic spectrophotoscopic method and magnetic susceptibility. 


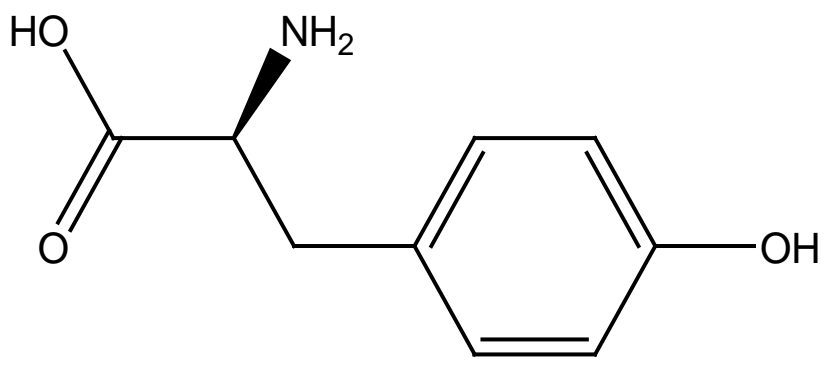

Figure 1. ( \pm )-2-amino-3-(4-hydroxyphenyl)propionic acid.

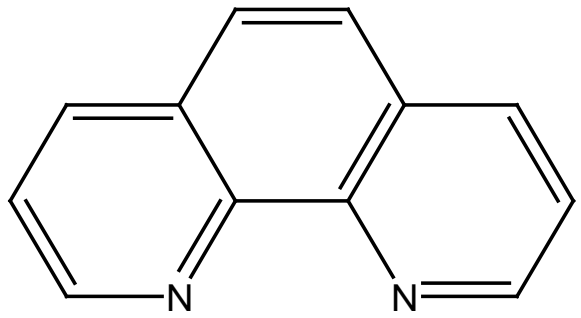

Figure 2. 1,10-phenantroline.

\section{Materials and Method}

All materials used are of high analytical grade. Melting points were determined in an open capillary tube on a Gallenkamp (Variable heater) melting point apparatus. The infrared spectra of all synthesized product and their ligands and magnetic susceptibility measurement of the metal complexes were done at the Department of Chemistry, Kwara state University Ilorin, Nigeria. The electronic spectra of all the compounds were run in solution in the wavelength range 400 $1000 \mathrm{~nm}$ at the Department of Chemistry North West University, Mafikeng Campus; South Africa. The antimicrobial screening and antioxidant activity for all the complexes was carried out in the Department of Pharmaceutics and Department of Biochemistry and Molecular Biology respectively at Obafemi Awolowo University, Ile Ife, Osun State, Nigeria.

The equations of the reactions are given in Equations (1)-(6).

$$
\begin{array}{ll}
\mathrm{CoCl}_{2}+3 \mathbf{L}^{1} \rightarrow\left[\mathrm{Co}\left(\mathbf{L}^{1}\right)_{2}\right] & \text { (Compound 1) } \\
\mathrm{CoCl}_{2}+2 \mathbf{L}^{1}+\mathbf{L}^{2} \rightarrow\left[\mathrm{Co}\left(\mathbf{L}^{1} \mathbf{L}^{2}\right)_{2}\right]_{2} & \text { (Compound 2) } \\
\mathrm{CuCl}_{2}+3 \mathbf{L}^{1} \rightarrow\left[\mathrm{Cu}\left(\mathbf{L}^{1}\right)_{3}\right] \mathrm{Cl} & \text { (Compound b) } \\
\mathrm{CuCl}_{2}+2 \mathbf{L}^{1}+\mathbf{L}^{2} \rightarrow\left[\mathrm{Cu}\left(\mathbf{L}^{1}\right)_{2} \mathbf{L}^{2}\right] & \text { (Compound 4) } \\
\mathrm{NiCl}_{2}+3 \mathbf{L}^{1} \rightarrow\left[\mathrm{Ni}\left(\mathbf{L}_{3}^{1}\right)_{3}\right] \mathrm{Cl} & \text { (Compound 5) } \\
\mathrm{NiCl}_{2}+2 \mathbf{L}^{1}+\mathbf{L}^{2} \rightarrow\left[\mathrm{Ni}\left(\mathbf{L}^{1}\right)_{2} \mathbf{L}^{2}\right] & \text { (Compound 6) }
\end{array}
$$

where: $\mathrm{L}^{1}=( \pm)$-2-amino-3-(4-hydroxyphenyl)propionic acid

$$
\mathrm{L}^{2}=1,10 \text {-phenantroline }
$$




\subsection{Syntheses of Compounds}

\subsubsection{Synthesis of Compound 1}

A cloudy solution of ( \pm )-2-amino-3-(4-hydroxyphenyl)propionic acid (5.81 g, $0.03 \mathrm{M}$ ) in $10 \mathrm{ml}$ of distilled water methanol mixture 3:1 ( $\mathrm{vol} / \mathrm{vol})$, in a flat bottom flask was heated and stirred. A solution of $2.37 \mathrm{~g}, 0.01 \mathrm{M}$ of cobalt(II) chloride hexahydrate was then added drop-wise to the solution of ( \pm )-2-amino-3(4-hydroxyphenyl)propionic acid. The mixture obtained was stirred and refluxed for $4 \mathrm{hrs}$. A light pink precipitate was obtained washed with methanol and dried in a desiccator. Yield: $0.74 \mathrm{~g}, 35 \%$; M.pt $/ \mathrm{dt}: 258^{\circ} \mathrm{C}$. The product obtained was soluble in water and insoluble in ethanol, methanol.

\subsubsection{Synthesis of Compound 2}

A cloudy solution of $( \pm$ )-2-amino-3-(4-hydroxyphenyl)propionic acid (3.66 g, $0.02 \mathrm{M}$ ) was poured in a beaker and $0.84 \mathrm{~g}, 0.02 \mathrm{M}$ of $\mathrm{NaOH}$ was added and stirred to give a clear solution. A solution of $1.85 \mathrm{~g}, 0.01 \mathrm{M}$ of 1,10-phenanthroline was also prepared separately. A solution of cobalt(II) chloride hexahydrate $2.39 \mathrm{~g}$, $0.01 \mathrm{M}$ was poured into a flat bottom flask and stirred. Both the ( \pm )-2-amino-3(4-hydroxyphenyl)propionic acid and 1,10-phenanthroline solution were then added drop wise and then stirred and refluxed for $4 \mathrm{hrs}$. The brown precipitate obtained was cooled and washed with ethanol:water mixture $(20: 80 \mathrm{v} / \mathrm{v})$ and dried in a desiccator. Yield: $2.81 \mathrm{~g}, 65.8 \%$; M.pt $/ \mathrm{dt}: 278^{\circ} \mathrm{C}-279^{\circ} \mathrm{C}$. Compound 2 was soluble in ethanol, methanol and insoluble in water.

Similar procedure was used for the preparation of the under listed complexes.

\subsubsection{Synthesis of Compound 3}

A solution of cobalt(II) chloride dihydrate $(1.70 \mathrm{~g}, 0.01 \mathrm{M})$ was added to $( \pm)-2$ amino-3-(4-hydroxyphenyl)propionic acid $(5.45 \mathrm{~g}, 0.01 \mathrm{M})$ and afforded a dark blue precipitate of the complex product. Yield: $1.11 \mathrm{~g}, 70 \%$; M.p/dt: $283^{\circ} \mathrm{C}$ (d). The product obtained was soluble in water and insoluble in ethanol, methanol.

\subsubsection{Synthesis of Compound 4}

Cobalt(II) chloride dihydrate $(1.71 \mathrm{~g}, 0.01 \mathrm{M})$ added to $( \pm)$-2-amino-3-(4-hydroxyphenyl)propionic acid 3.84, $0.1 \mathrm{M}$ and 1,10-phenanthroline $(1.81 \mathrm{~g}, 0.01$ M) to afford a light blue of the complex product. Yield: 2.20 g, 78\%; M.pt/dt: $303^{\circ} \mathrm{C}$. The product obtained was soluble in water and insoluble in ethanol, methanol.

\subsubsection{Synthesis of Compound 5}

Nickel(II) chloride hexahydrate $(1.20 \mathrm{~g}, 0.005 \mathrm{M})$ solution was added to ( \pm )-2-amino-3-(4-hydroxyphenyl)propionic acid $(2.80 \mathrm{~g}, 0.015 \mathrm{M})$ to afford a pale green product. Yield: $1.01 \mathrm{~g}, 73 \%$; M.pt $/ \mathrm{dt}: 317^{\circ} \mathrm{C}$ (d). The product obtained was soluble in water and insoluble in ethanol, methanol.

\subsubsection{Synthesis of Compound 6}

Nickel(II) chloride hexahydrate $(2.39 \mathrm{~g}, 0.01 \mathrm{M})$ added to a mixed ligand of ( \pm )-2-amino-3-(4-hydroxyphenyl)propionic acid (3.71 g, $0.02 \mathrm{M})$ and 1,10-phe- 
nanthroline $(1.82 \mathrm{~g}, 0.01 \mathrm{M})$ a gave a pale green of the complex product. Yield: 2.02 g, $71 \%$; M.pt $/ \mathrm{dt}: 294^{\circ} \mathrm{C}$. The product obtained was soluble in water and insoluble in ethanol, methanol.

\subsection{Antioxidant Activity Determination}

\subsubsection{Determination of Total Phenol Content}

The method of determining the total phenolic content was described by Singleton and Rossi, 1965, Gulcin et al., (2004) [19] [20] using the folin ciocalteu's phenol reagent which is an oxidizing reagent. To a mixture of $0.1 \mathrm{ml}$ of sample and $0.9 \mathrm{ml}$ of water was added $0.2 \mathrm{ml}$ of folin-ciocalteu's phenol reagent and the resulting mixture voltexed. After 5 minutes of standing, $1.0 \mathrm{ml}$ of $7 \%$ (w/w) $\mathrm{Na}_{2} \mathrm{CO}_{3}$ solution then added and the solution was then distilled to $2.5 \mathrm{ml}$ before incubation for $90 \mathrm{~min}$ at room temperature. The absorbance against a negative control containing $1 \mathrm{ml}$ of water in place of the sample was then taken at $750 \mathrm{~nm}$. The standard used was the Gallic acid at $0.1 \mathrm{mg} / \mathrm{ml}$ in order to determine Gallic acid Equivalent (GAE) of sample, after preparing a calibration curve. Distilled water was used as blank.

\subsubsection{DPPH Assay}

The radical scavenging ability of the compounds was determined using the stable radical DPPH (2,2-diphenyl-1-picrylhydrazyl hydrate) as described by BrandWilliams et al., (1995) [21]. The reaction of DPPH with an antioxidant compound which can donate hydrogen, leads to its reduction (Blois, 1958) [22]. The change in colour from deep violet to light yellow was measured spectrophotometrically at $517 \mathrm{~nm}$. To $1.0 \mathrm{ml}$ of different concentrations $(10,5,2.5,1.25,0.625,0.3125$ $\mathrm{mg} / \mathrm{ml}$ ) of the compounds or standard (vitamin C) in a test tube was added 1.0 $\mathrm{ml}$ of $0.3 \mathrm{mM} \mathrm{DPPH}$ in methanol. The mixture was mixed and incubated in the dark for 30mins after which the absorbance was read at $517 \mathrm{~nm}$ against a DPPH control containing only $1.0 \mathrm{ml}$ methanol in place of the compounds. The percent of inhibition was calculated using the formula

$$
I \%=\left[\left(A_{\text {blank }}-A_{\text {sample }}\right) / A_{\text {blank }}\right] \times 100
$$

where:

$A_{\text {blank }}=$ the absorbance of the control reaction (containing all reagents except the test compound);

$A_{\text {sample }}=$ the absorbance of the test compound.

Sample concentration providing $50 \%$ inhibition $\left(\mathrm{IC}_{50}\right)$ was calculated from the graph plotting inhibition percentage against concentration of the compound.

\subsubsection{Determination of Total Antioxidant Capacity Using Phosphomolybdenum Method}

A solution of the reagent $(1.0 \mathrm{ml})$; constituting $0.6 \mathrm{M}$ sulphuric acid, $28 \mathrm{mM}$ sodium phosphate $\left(\mathrm{NaH}_{2} \mathrm{PO}_{4} \cdot 2 \mathrm{H}_{2} \mathrm{O}\right)$ and $4 \mathrm{mM}$ ammonium molybdate, was added to $0.1 \mathrm{ml}$ of the compounds or standard solutions of ascorbic acid $(20,40,60,80$, $100 \mu \mathrm{g} / \mathrm{ml}$ ) was added. The tubes containing the reacting mixture were incubated 
in a water bath at $95^{\circ} \mathrm{C}$ for 90 mins. The mixture was then allowed to stand and cool to room temperature and the absorbance measured at $695 \mathrm{~nm}$ against a blank which consisted of the reacting mixture containing distilled water in place of the compounds. The antioxidant activities of the extracts were expressed as an ascorbic acid equivalent.

\subsubsection{Determination of Ferric Reducing Antioxidant Power (FRAP)}

This was carried out as described by Benzie and Strain, 1999 [23]. A $300 \mathrm{mmol} / \mathrm{L}$ acetate buffer of pH 3.6, $10 \mathrm{mmol} / \mathrm{L} \mathrm{2,} \mathrm{4,} \mathrm{6-tri-(2-pyridyl)-1,} \mathrm{3,} \mathrm{5-triazine} \mathrm{and} 20$ $\mathrm{mmol} / \mathrm{L} \mathrm{FeCl}_{3} \cdot 6 \mathrm{H}_{2} \mathrm{O}$ were mixed together in the ratio of 10:1:1 respectively, to give the working FRAP reagent. A $50 \mu \mathrm{l}$ aliquot of the oil extract at $0.1 \mathrm{mg} / \mathrm{ml}$ and $50 \mu \mathrm{l}$ of standard solutions of ascorbic acid $(20,40,60,80,100 \mu \mathrm{g} / \mathrm{ml})$ was added to $1.0 \mathrm{ml}$ of FRAP reagent. Absorbance measurement was taken at $593 \mathrm{~nm}$ exactly 10 minutes after mixing against reagent blank containing $50 \mu \mathrm{l}$ of distilled water.

All measurements were taken at room temperature with samples protected from direct sunlight. The reducing power was expressed as equivalent concentration (EC) which is defined as the concentration of antioxidant that gave a ferric reducing ability equivalent to that of the ascorbic acid standard.

\subsection{Antimicrobial Methodology}

The organisms used were five Gram-positive and three Gram-negative bacteria and two fungi. These were $S$. aureus, $S$. epidermidis, B. subtilis 12 , B. subtilis 82 , Clostridium sp., K. pneumonia, $P$. aeruginosa, E. coli, $C$. albicans and $C$. pseudotropicalis, respectively. The agents were dissolved in water at room temperature or hot water as appropriate to give a concentration of $40 \mathrm{mg} / \mathrm{ml}$. The resulting solutions were used to soak sterile Whatman No 2 discs (diameter of $6 \mathrm{~mm}$ ) and allowed to dry in an oven at $50^{\circ} \mathrm{C}$. The discs were then utilized to determine antibacterial and antifungal activities as previously described by Aiyelabola et al. 2012 [24]. Discs that were impregnated with imipenem and chlorhexidine were used as positive controls for bacteria and fungi respectively. Zones of inhibition were used as indices of antimicrobial actions.

\section{Result and Discussion}

\subsection{Infrared Spectra}

The relevant vibrational frequencies in the infrared spectra of the ligands and complexes and their assignments are summarized in Table 1. Information about the metal ions coordination was obtained by comparing the IR frequencies of the ligands with those of the metal complexes.

\subsection{1. ( \pm )-2-Amino-3-(4-Hydroxyphenyl)Propionic Acid Complexes}

In the spectrum of ( \pm )-2-amino-3-(4-hydroxyphenyl)propionic acid the phenolic $v(\mathrm{O}-\mathrm{H})$ and the $(\mathrm{N}-\mathrm{H})$ stretching vibration frequency of the zwitterionic amine appeared at 3205 and $3126 \mathrm{~cm}^{-1}$ respectively [21] [22]. Both stretching frequencies 
Table 1. Relevant infrared spectra bands for the ligands and complexes $\left(\mathrm{cm}^{-1}\right)$.

\begin{tabular}{|c|c|c|c|c|c|c|c|c|c|}
\hline Bands & $v(\mathrm{O}-\mathrm{H})$ & $v_{\mathrm{as}}(\mathrm{N}-\mathrm{H})$ & $v_{\mathrm{sy}}(\mathrm{N}-\mathrm{H})$ & $v_{\mathrm{as}}(\mathrm{COO})\left(\mathrm{cm}^{-1}\right)$ & $v_{\mathrm{sy}}(\mathrm{COO})$ & $\mathrm{N}(\mathrm{C}=\mathrm{N})$ & $v(\mathrm{C}-\mathrm{N})$ & $v(\mathrm{M}-\mathrm{N})$ & $v(\mathrm{M}-\mathrm{O})$ \\
\hline $\mathrm{L}^{\prime}$ & 3205 & 3126 & & 1650 & 1583 & & & & \\
\hline $\mathrm{L}^{\prime \prime}$ & & & & & & 1514,1330 & & & \\
\hline 1 & 3550 & 3354 & 3324 & 1640,1424 & 1585,1359 & & 1246,1174 & 649 & 575,532 \\
\hline 2 & & & 3150 & 1654 & 1516,1375 & 1430 & 1244,1108 & 370 & 513 \\
\hline 3 & 3515,3442 & 3205 & & 1588,1452 & 1513,1434 & & 1244,1042 & 649 & 575,530 \\
\hline 4 & 3309 & 3234 & 3158 & 1583,1459 & 1352 & 1403 & 1302,1235 & 638,604 & 541,517 \\
\hline 5 & 3590 & 3328 & 3278 & 1598,1448 & 1515,1384 & & 1145 & 604 & 535 \\
\hline 6 & 3660 & 3340 & 1586 & 1514 & 1424,1359 & 1330 & 1143 & 642 & 530 \\
\hline
\end{tabular}

were observed at lower frequencies than expected. It is however suggested that this may be as a result of intramolecular hydrogen bonding between the hydrogen atom of the positively charged amine substituent and the oxygen atom of phenol [25] [26]. The deprotonation of the cationic amine and consequently the loss of this hydrogen bond is suggested by the resultant increment in these absorption frequencies in the spectra of the complexes (Table 1). The occurrence of the $v(\mathrm{~N}-\mathrm{H})$ of the amino substituent at higher energies at about $40 \mathrm{~cm}^{-1}$ in case of the cobalt(II) and copper(II) complexes as compared to the free ligand suggest the bonding of amino nitrogen atom to the metal ion. Thus indicating deprotonation followed by coordination through the nitrogen atom [26]. This is in consonance with the reduction in the bond length of the N-H bond as a result of coordination. However, the nickel(II) complex did not exhibit this band, it is suggested that this may be as a result of the anomalous behavior of the complex or the masking of this peak by others as well as intermolecular interactions. The former argument is however supported by the observed magnetic moment [27].

The $\mathrm{COO}^{-}$stretching frequencies of complexes of amino acids have been reported to be affected by coordination and therefore are useful tools in the structural elucidation of amino acids complexes [26] [28]. Evidence of the coordination of $\mathrm{COO}$ was provided by the asymmetric and symmetric vibrations of $\mathrm{COO}$ group. The absorption bands at 1650 and $1583 \mathrm{~cm}^{-1}$ in the free ligand are attributed to the $\mathrm{COO}^{-}$asymmetric and symmetric stretching frequencies, respectively. The $\mathrm{COO}^{-}$asymmetric for stretching frequency was shifted to higher frequencies for compounds 5 and 3, however for compound 1 it shifted to lower frequency. The $\mathrm{COO}^{-}$symmetric for stretching frequency was shifted to lower frequencies for all the complexes. The observed shifts for compounds 5 and 3 indicated the monodenticity of the carboxylate ion on coordination [29] [30] [31] [32] [33]. On the other hand it suggests probable polymerization or dimerization for compound 1, this was suggested by the lowering of the asymmetric stretching frequency. Corroborating the suggested coordination of the nitrogen and oxygen atoms was the observed metal-nitrogen (M-N) and metal-oxygen (M-O) bonds around $610-682 \mathrm{~cm}^{-1}$ and $570-575 \mathrm{~cm}^{-1}$ respectively [26]. 


\subsubsection{Mixed Ligand Complexes}

The $v(\mathrm{O}-\mathrm{H})$ band observed at $3205 \mathrm{~cm}^{-1}$ in the spectrum of $( \pm)$-2-amino-3-(4hydroxyphenyl)propionic acid was shifted to higher frequencies in these complexes, similar to their binary counterpart. Although compound 2 did not exhibit this frequency, it is suggested that this may be an indication of the deprotonation of the phenolic substituent by the base [25] [26]. The N-H stretching frequency observed as a strong band at $3126 \mathrm{~cm}^{-1}$ in the spectrum of ( \pm )-2-amino-3-(4-hydroxyphenyl)propionic acid was shifted to lower regions in the cobalt complex suggesting the addition of the Lewis base to the metal ion [25] [26]. This indicates the elongation of the N-H bond. In the case of the copper(II) complex this band shifted to higher frequency suggestive of reduction of bonds, this also serves as evidence of coordination of the nitrogen atom to the metal ion. Similar to that observed for compound 5 the spectrum for compound 6 did not exhibit this frequency; this has been attributed to the anomalous behavior of nickel which was also corroborated by its observed magnetic moment [27].

In this instance, for the mixed ligand complexes the $v_{\text {sym }}\left(\mathrm{COO}^{-}\right)$absorption was shifted to higher position by $(136) \mathrm{cm}^{-1}$ while the band caused by $v_{\text {asym }}\left(\mathrm{COO}^{-}\right)$ lowered by (49-30) $\mathrm{cm}^{-1}$ as compared with the free ligand. This therefore indicates the coordination of the carboxylate group to the central metal ion [26]. The monodentate nature of the $\mathrm{COO}^{-}$functionality is suggested by the hypsochromic shifts in the $v_{\text {asym }}\left(\mathrm{COO}^{-}\right)$frequency and bathochromic shift for the $v_{\text {sym }}\left(\mathrm{COO}^{-}\right)$ frequency for compounds 2, 4 and 6 indicated the monodenticity of the carboxylate ion on coordination [29] [30] [31] [32].

Additionally further confirmation of the coordination of amino nitrogen and carboxylate oxygen is given by the observance of metal-nitrogen (M-N) and metal-oxygen at 600 and $500 \mathrm{~cm}^{-1}$ respectively. Evidence for the coordination of 1,10-phenanthroline and thus the formation of mixed ligand complexes, was observed in the shift in the $v(\mathrm{C}=\mathrm{N})$ ring vibrations of the uncoordinated 1,10-phenanthroline (Table 1) [26].

\subsection{Electronic Spectra}

The electronic spectra of the ligands showed two absorption bands at 265, 286 $\mathrm{nm}$ for ( \pm )-2-amino-3-(4-hydroxyphenyl)propionic acid 181.19 attributed to $\pi$ $\rightarrow \pi^{*}$ and $\mathrm{n} \rightarrow \pi^{*}$ transitions and that of 1,10-phenanthroline at $310,324 \mathrm{~nm}$ attributed to $\pi \rightarrow \pi^{*}$ and $n \rightarrow \pi^{*}$ transitions of the major chromophores, $-\mathrm{NH}_{2}$, $-\mathrm{CN}$ and $\mathrm{COO}^{-}$[25]. However on coordination, shifts in the bands were observed. Measurements of the effective magnetic moments of coordination compounds can be used to estimate the number of unpaired electrons. The stereochemistry and bond type of the coordinated metal ion can then be determined with the aid of valence bond or crystal field theory [27].

The electronic spectrum of compound 1 exhibited two bands at $512 \mathrm{~nm}$ and $735 \mathrm{~nm}$ corresponding to ${ }^{2} \mathrm{~A}_{1 \mathrm{~g}} \rightarrow{ }^{2} \mathrm{~B}_{2 \mathrm{~g}}$ and ${ }^{2} \mathrm{~A}_{1 \mathrm{~g}} \rightarrow{ }^{2} \mathrm{E}_{1 \mathrm{~g}}$ respectively On the basis of simplest model three spin-allowed bands are expected in a four coordinate cobalt(II) complex, that is, ${ }^{4} \mathrm{~A}_{2}(\mathrm{~F}) \rightarrow{ }^{4} \mathrm{~T}_{2}(\mathrm{~F}),{ }^{4} \mathrm{~A}_{2}(\mathrm{~F}) \rightarrow{ }^{4} \mathrm{~T}_{1}(\mathrm{~F})$, and ${ }^{4} \mathrm{~A}_{2}(\mathrm{~F}) \rightarrow{ }^{4} \mathrm{~T}_{1}(\mathrm{P})$. 
Usually such complexes show two bands between 830 and $625 \mathrm{~nm}$, which can be assigned to ${ }^{4} \mathrm{~A}_{2}(\mathrm{~F}) \rightarrow{ }^{4} \mathrm{~T}_{2}(\mathrm{~F})$ and ${ }^{4} \mathrm{~A}_{2}(\mathrm{~F}) \rightarrow{ }^{4} \mathrm{~T}_{1}(\mathrm{~F})$, respectively; ${ }^{4} \mathrm{~A}_{2}(\mathrm{~F}) \rightarrow{ }^{4} \mathrm{~T}_{1}(\mathrm{P})$ is usually observed as a well-defined shoulder at about $550 \mathrm{~nm}$ [31]. The UV-visible spectrum of complex (1) exhibited bands at $512 \mathrm{~nm}$ and $735 \mathrm{~nm}$ corresponding to ${ }^{2} \mathrm{~A}_{1 \mathrm{~g}} \rightarrow{ }^{2} \mathrm{~B}_{2 \mathrm{~g}}$ and ${ }^{2} \mathrm{~A}_{1 \mathrm{~g}} \rightarrow{ }^{2} \mathrm{E}_{1 \mathrm{~g}}$ respectively. Absorption at $259 \mathrm{~nm}$ is ascribed to transitions $\pi \rightarrow \pi^{*}$ and $n \rightarrow \pi$ of the ligand [32] [33]. It exhibited a magnetic moment of 2.66 BM suggestive of diametric, square planar. The subnormality in magnetic moments may be ascribed to antiferromagnetism which is due to the interaction between electron spins on neighbouring metal ions or polymerization. It is generally accepted that the mechanism of the exchange interactions involves the mutual pairing of electron spins via orbital overlap. Antiferromagnetic exchange may be metal-metal interaction or super exchange. Metal-metal interactions involve direct overlap of orbitals containing the unpaired electrons, which influences the magnetic behavior whereas super exchange involves the interaction of electrons with opposite spins on the two interacting ions via an intermediate diamagnetic anion(s) which results in effective pairing leading to a minimum number of unpaired spins in the ground state of the system. Both the mechanisms seem to be operative, thereby leading to the observed magnetic moment [34] [35] [36].

The spectrum for the cobalt(II) complex of the mixed ligand, compound 2, showed two bands at $460 \mathrm{~nm}$ and $620 \mathrm{~nm}$ corresponding to the transitions ${ }^{3} \mathrm{~A}_{2} \mathrm{~g}$ $\rightarrow{ }^{3} \mathrm{~T}_{2} \mathrm{~g}$ and ${ }^{4} \mathrm{~A}_{2} \mathrm{~g} \rightarrow{ }^{3} \mathrm{~T}_{1} \mathrm{~g}$ respectively for octahedral geometry [27]. Absorption at 259 and $318 \mathrm{~nm}$ is associated with $\pi \rightarrow \pi^{*}$ transition of the ligand [43] [44] Its magnetic moment of $1.066 \mathrm{BM}$ is lower than that expected for $\mathrm{Co}$ (II) ion may be ascribed to antiferromagnetism which is due to the interaction between electron spins on neighbouring metal ions or polymerization. This is similar to that obtained for compound 1 [34] [35] [36].

The electronic spectrum of compound 3 showed a well resolved band at 499 $\mathrm{nm}$ and a weak band at $517 \mathrm{~nm}$ typical for a tetragonally distorted octahedral configuration and may be assigned to ${ }^{2} \mathrm{~B}_{1 \mathrm{~g}} \rightarrow{ }^{2} \mathrm{~A}_{1 \mathrm{~g}}$ and ${ }^{2} \mathrm{~B}_{1 \mathrm{~g}} \rightarrow{ }^{2} \mathrm{E}_{\mathrm{g}}$ transitions [27]. The observed magnetic moment 2.17 $\mathrm{BM}$ is therefore indicative of an unpaired electron as expected for a $d^{A}$ system. And is consistent with an octahedral geometry and is in agreement with previous reports [27] [37].

The spectrum for compound 4 exhibited absorption band at $620 \mathrm{~nm}$ attributed to ${ }^{2} \mathrm{E}_{\mathrm{g}} \rightarrow{ }^{2} \mathrm{~T}_{2} \mathrm{~g}$ at the $\mathrm{d}$ - $\mathrm{d}$ transition for octahedral geometry. Absorption at 259 and $330 \mathrm{~nm}$ are associated with $\pi \rightarrow \pi^{*}$ and $\mathrm{n} \rightarrow \pi^{*}$ transitions of the ligands [27] [33]. Its magnetic moment of $2.40 \mathrm{BM}$ suggests Jahn Teller distorted octahedral geometry. This is in agreement with previous reports [38] [39].

The spectrum of compound 5 elicited bands at 476 and $512 \mathrm{~nm}$ attributed to ${ }^{3} \mathrm{~A}_{2 \mathrm{~g}} \rightarrow{ }^{3} \mathrm{~T} 1_{\mathrm{g}}$ and ${ }^{3} \mathrm{~A}_{2 \mathrm{~g}} \rightarrow{ }^{3} \mathrm{~T}_{2 \mathrm{~g}}{ }^{3} \mathrm{~A}_{2 \mathrm{~g}}(\mathrm{~F}) \rightarrow{ }^{5} \mathrm{~T}_{1 \mathrm{~g}}(\mathrm{~F})$ and ${ }^{3} \mathrm{~A}_{2 \mathrm{~g}}(\mathrm{~F}) \rightarrow{ }^{5} \mathrm{~T}_{1 \mathrm{~g}}(\mathrm{P})$ suggestive of an octahedral geometry respectively suggestive of an octahedral geometry. Absorption at $259 \mathrm{~nm}$ is associated with $\pi \rightarrow \pi^{*}$ and $\mathrm{n} \rightarrow \pi^{*}$ transitions of the ligand [27] [33]. There is no clear cut distinction between the magnetic moments of tetrahedral and octahedral nickel(II) complexes. This is because they both have the 
same number of unpaired electrons in the $d$-orbital. On the other hand the square planar complex is however diamagnetic. A magnetic moment of $2.22 \mathrm{BM}$ was obtained for compound 5 indicative of a mixture of octahedral geometry [27].

The nickel(II) complex of the mixed ligands showed a band at $636 \mathrm{~nm}$ which corresponds to the transition ${ }^{3} \mathrm{~A}_{2 \mathrm{~g}} \rightarrow 3 \mathrm{~T}_{1 \mathrm{~g}}$ for octahedral geometry [27]. Absorption at 259 and $332 \mathrm{~nm}$ is associated with $\pi \rightarrow \pi^{*}$ transition of the ligand. The complex elicited a magnetic moment of 1.66 BM. This may be interpreted as an indication of a low-spin-high-spin equilibrium mixture with $15 \%-20 \%$ paramagnetic nickel(II) species and agrees with what was reported by Woods and Patel (1994) to be octahedral in solution [27] [40].

Based on the results obtained a diametric square planar geometry is proposed for compound 1, with the ligand coordinating via the nitrogen atom of the amino moiety and the oxygen atom of the carboxylate ion. According to Nakamoto, 2009 it has been shown that the oxygen atoms of the carbonyl groups which are not coordinated to the central metal ion are hydrogen-bonded either to the amino group of the neighbouring molecule or to water of crystallization or are bound weakly to the metal of the neighbouring complex. It is proposed that such carbonyl is weakly bound to the metal of the neighbouring complex for this complex.

During the synthesis of compound 2, no reaction was observed on the addition of the reagents to the reaction medium. However, on basifying of the reaction by the addition of sodium hydroxide solution, a brown precipitate was obtained. There is no evident reason for this observation. We suggest that the addition of the base served as a catalyst, by lowering the activation energy of the reaction. The reason for this may partly be as a result of the larger size of the cobalt(II) ion in relation to the other metal ions used in this study. Furthermore, it is known that 1,10-phenantroline exhibit structure directing ability, it forms a chelate with the metal ion, such that the primary ligands may then occupy the other vacant positions [41] [42]. This thus indicates that an alkaline medium is more favourable for the synthesis of this mixed ligand complex. For compound 2 a diametric, square planar complex is also proposed. Although sodium hydroxide may have served as a catalyst for the reaction in obtaining compound 2 the dark drown coloration points to oxidation of the phenolic moiety by its deprotonation. It is further proposed that the primary ligand coordinated using the amino nitrogen and a carboxylate oxygen atom. Similar to what obtained for compound 1.

We further propose an octahedral geometry for compounds 3, 4 and 6. Additionally a square planar geometry is suggested for compound 5 .

\subsection{Antioxidant Activity}

Four assays for evaluating antioxidant capacity of the compounds was applied namely DPPH, TRAP, TAC and FRAP. The results obtained are presented in Tables 2-5. 


\subsubsection{Total Phenolic Content}

It is well known that phenolic compounds are potential antioxidants; free radical scavengers, as such there should be a close correlation between the content of phenolic compounds and antioxidant activity. In this present study, the total phenolic content of the compounds was investigated with compound 2 having the highest total phenolic content followed by compound 1 and compound 5 with the least activity. Order of activity is as follows $2>1>6>3>4>5$. Thus indicating that compound 1 may have the most outstanding antioxidant activity. This is not quite surprising and supports the hypothesis that the phenolic $\mathrm{OH}$ in the case of compound 2 is deprotonated and not coordinated to any central atom [12] [13] [14]. Therefore it is more readily available relative to compound 1. As a consequence the result obtained serves to corroborate the deprotonation of the hydroxyl moiety in compound 2.

\subsubsection{DPPH Radical Scavenging Activity}

DPPH has been widely used for free radical scavenging assessment due to its ease and convenience. In this study all the synthesized compounds were found to be effective DPPH radical scavengers. The activity of the complexes was more superior to the standard, ascorbic acid $\left(\mathrm{IC}_{50}=1.603\right)$, with order of activity; $2>$ $1>6>3>4>5$. This result positively correlates with that obtained with total phenolic content.

\subsubsection{FRAP}

The ferric ion reducing antioxidant power assay is used to determine the electron donating ability, of the matrix. The FRAP assay uses antioxidants as reductants in a redox-linked colorimetric method with absorbance measured with a spectrophotometer [23]. The principle of this method is based on the reduction of a colourless ferric-tripyridyltriazine complex to its blue ferrous coloured form owing to the action of electron donation in the presence of antioxidants. In this case compound 2 exhibited the best activity. Order of activity was $2>1>4>6>3>5$.

\subsubsection{Total Antioxidant Capacity Using Phosphomolybdenum Method} This method is based on the reduction of molybdenum(VI) to molybdenum(V) by the compounds and the subsequent formation of a green phosphate/Molybdenum(V) complex at an acidic $\mathrm{pH}$ [43]. The observed activity was of the order $2>1>6>3>4>5$.

Table 2. Total phenolic content of the compounds based on gallic acid equivalent.

\begin{tabular}{ccc}
\hline Compound & GAE mg/g & SD \\
\hline $\mathbf{1}$ & 41.42029 & 0.05124 \\
$\mathbf{2}$ & 44.15580 & 0.677836 \\
$\mathbf{3}$ & 40.31522 & 0.247069 \\
$\mathbf{4}$ & 38.34058 & 0.338918 \\
$\mathbf{5}$ & 17.09058 & 0.446697 \\
$\mathbf{6}$ & 40.78623 & 0.252326 \\
\hline
\end{tabular}


Table 3. The $\mathrm{IC}_{50}$ values of DPPH scavenging effect of the compounds.

\begin{tabular}{ccc}
\hline Compound & $\mathrm{IC}_{50} \mu \mathrm{g} / \mathrm{mL}$ & $\mathrm{SD}$ \\
\hline $\mathbf{1}$ & 0.680772 & 0.010003 \\
$\mathbf{2}$ & 0.567218 & 0.056051 \\
$\mathbf{3}$ & 0.741618 & 0.003939 \\
$\mathbf{4}$ & 0.742452 & 0.038416 \\
$\mathbf{5}$ & 3.729431 & 0.218153 \\
$\mathbf{6}$ & 0.537161 & 0.003352
\end{tabular}

Control $=1.603$

Table 4. Ferric reducing antioxidant power (FRAP) of the compounds based on ascorbic acid equivalent.

\begin{tabular}{ccc}
\hline Compound & AAE mg/g & SD \\
\hline $\mathbf{1}$ & 30.03855 & 2.531966 \\
$\mathbf{2}$ & 55.18612 & 6.012896 \\
$\mathbf{3}$ & 11.63715 & 0.414038 \\
$\mathbf{4}$ & 16.33538 & 0.651527 \\
$\mathbf{5}$ & 10.04096 & 0.641001 \\
$\mathbf{6}$ & 18.53391 & 1.951098 \\
\hline
\end{tabular}

Table 5. Total antioxidant capacity of the compounds based on ascorbic acid equivalent.

\begin{tabular}{ccc}
\hline Compound & AAE mg/g & SD \\
\hline $\mathbf{1}$ & 43.34801 & 10.1557 \\
$\mathbf{2}$ & 48.68562 & 9.58751 \\
$\mathbf{3}$ & 25.06672 & 2.732265 \\
$\mathbf{4}$ & 20.06272 & 1.702342 \\
$\mathbf{5}$ & 10.58847 & 3.126601 \\
$\mathbf{6}$ & 36.87617 & 7.783973
\end{tabular}

To date, there are various antioxidant activity assays, each one having their specific target within a given matrix, all of them with advantages and disadvantages. There is no method that can provide unequivocal results and the best solution is to use various methods instead of one dimensional approach [43] [44]. In this regard more than one antioxidant assay was used for more detailed understanding of the antioxidant properties of samples. The results obtained showed that the TPC indicated good correlation with DPPH, TAP and with some compounds with FRAP. However no significant correlation existed between the result obtained for compound 3 and 4 using FRAP and other methods of antioxi- 
dant. This agrees with reports indicating that different results can be obtained when different assays are applied to measure antioxidant activity [43] [44].

For all the assays compound 2 exhibited the highest activity. This is may be unexpected as two molecules of the primary ligand is proposed for this compound in relation to compound 1 which is proposed to have three phenolic $-\mathrm{OH}$. We propose that these phenolic $-\mathrm{OH}$ in compound 1 are coordinated to neighbouring central metal ion. This is supported by the magnetic moment and infrared spectra. The result obtained for the four assays indicated that compound 5 exhibited the least activity. The reason for this is not readily evident. However, this suggests that the geometry assumed by a coordination compound is a function of the central metal ion and as a consequence, its functionality [45] [46] [47]. The result obtained for the antioxidant properties of the compounds may therefore as a result be ascribed to the varying molecular structures assumed by each compound. The results obtained further validates the anti-oxidant activity of phenolic substituents [12] [13] [14]. Further studies on the antioxidant are however suggested for this compound.

For the entire four assays compound 5 exhibited the least activity, this observed activity validates the proposed geometry for the complex. The lower activity of compounds 3 and 4, copper complexes with octahedral geometry in comparison with compound 6, the mixed ligand complex, alludes to the individualistic nature of the central metal ion in defining the geometry of a given complex and as a consequence its activity [45] [46]. This may be exemplified by the activity of cisplatin, with platinum as the central metal ion, the use of other metal ions as the central metal resulted in their null or lower activity in comparison with cisplatin [47] [48].

\subsection{Antibacterial Activity Testing}

A comparison of the antimicrobial activity of the complexes against the reference antibiotic demonstrated that the standards drug used imipenem and chlorhexidine elicited significantly better antimicrobial than the synthesized complexes and ligands, (Table 6). The ligands ( \pm )-2-amino-3-(4-hydroxyphenyl)propionic acid did not exhibit any activity while o-phenantroline exhibited significant antimicrobial activity (Table 6). On coordination however the complexes had enhanced antimicrobial activity in some cases. This increase in antibacterial activity can be explained on the basis of Overtone's concept and Tweedy's chelation theory [49] [50]. The lipid membrane that surrounds the cell favors the passage of lipid soluble materials. As such this may be a factor for antimicrobial activity. On coordination, the polarity of the metal ion is reduced to a greater extent due to the overlap of the ligand orbitals and partial sharing of the positive charge of the metal ion with the donor groups. Furthermore, it increases the delocalization of $\pi$ electrons over the whole chelate ring and hence enhances the liposolubility of the complexes. This increased liposolubility enhances the penetration of the complexes into the lipid membrane and the complex interferes in the normal activities of the bacteria [49] [50]. 
Table 6. Result of zone of inhibition for antimicrobial ( $\mathrm{mm}$ ) for the ligands and complexes.

\begin{tabular}{cccccccccc}
\hline & $\mathrm{L}^{1}$ & $\mathrm{~L}^{2}$ & $\mathbf{1}$ & $\mathbf{2}$ & $\mathbf{3}$ & $\mathbf{4}$ & $\mathbf{5}$ & $\mathbf{6}$ & $\mathrm{C}$ \\
\hline S. aureus, & - & 38 & 09 & 07 & 08 & 06 & 07 & 04 & 44 \\
S. Epidermidis & - & 36 & 06 & - & - & - & 05 & - & 34 \\
B. subtilis 12 & - & 46 & 18 & 12 & 16 & 04 & 04 & - & 34 \\
B.subtilis 82 & - & 34 & 10 & - & 05 & 11 & - & - & 29 \\
Clostridium & - & - & 07 & 17 & 04 & - & 04 & 08 & 34 \\
K. Pneumonia & 09 & 42 & 04 & - & 09 & 08 & - & - & 34 \\
P. Aeruginosa & - & 10 & - & - & - & - & - & - & 39 \\
E. Coli & - & 32 & 09 & - & - & - & - & - & 33 \\
C. Albicans & - & 15 & 04 & - & - & - & - & - & 36 \\
C. pseudotropicalis. & - & - & - & - & - & 07 & - & - & 36 \\
\hline
\end{tabular}

where: $\mathbf{C}=$ imipenem and chlorhexidine for bacteria and fungi;

$\mathbf{L}^{1}=( \pm)$-2-amino-3-(4-hydroxyphenyl)propionic acid; $\mathbf{L}^{2}=1,10$-phenantroline.

The cobalt(II) ( \pm )-2-amino-3-(4-hydroxyphenyl)propionic acid complex elicited the best activity among all the complexes. On the other hand compound 6 exhibited the least activity of all the compounds. In some cases, chelation enhanced the activity of the coordination compounds relative to the ligand [49] [50]. The cobalt(II) ( \pm )-2-amino-3-(4-hydroxyphenyl)propionic acid complex exhibited better activity than the mixed ligand complex with the exception of the Clostridium. Mostly the ( \pm )-2-amino-3-(4-hydroxyphenyl)propionic acid were more active than their mixed ligand counterparts. In some cases, however the mixed ligand complexes exhibited a fairly better active compared with the 2-amino-3-(4-hydroxyphenyl)propionic acid complexes. The compounds were however not as effective as the standards imipenem and chlorhexidine against bacteria and fungi.

\section{Conclusion}

Coordination compounds of ( \pm )-2-amino-3-(4-hydroxyphenyl)propionic acid and their mixed ligand complex with 1,10-phenantroline were synthesized, characterized. The primary ligand coordinated via the nitrogen atom of the amino moiety and the oxygen atom of the carboxylate ion. On the other hand, the secondary ligand coordinated via the nitrogen atoms of the molecule. The result obtained indicated a diametric square planar geometry for both cobalt(II) $( \pm)$-2-amino-3-(4-hydroxyphenyl)propionic acid complex and its mixed ligand complex. Octahedral geometry was proposed for both copper complexes. Square planar for the nickel(II) ( \pm )-2-amino-3-(4-hydroxyphenyl)propionic acid complex and a mixture of square planar and octahedral geometry for the nickel mixed ligand complex. Although phenolic substituents have been related with anti-microbial and -oxidant activities, in this case the results obtained for both activities do not correlate with each other. Thus, this further corroborates the fact that the mode of activity of both biological activities may vary. 


\section{Conflicts of Interest}

The authors declare no conflicts of interest regarding the publication of this paper.

\section{References}

[1] Glans, L., Ehnbom, A. and de Kock, C. (2012) Ruthenium(II) Arene Complexes with Chelating Chloroquine Analogue Ligands: Synthesis, Characterization and in Vitro Antimalarial Activity. Dalton Transaction, 41, 2764-2773. https://doi.org/10.1039/c2dt12083f

[2] Vela, L., Contel, M., Palomera, L., Azaceta, G. and Marzo, I. (2011) IminophosphoraneOrganogold(III) Complexes Induce Cell Death through Mitochondrial ROS Production. Journal of Inorganic Biochemistry, 105, 1306-1313. https://doi.org/10.1016/j.jinorgbio.2011.06.004

[3] Allardyce, C.S. and Dyson, P.J. (2016) Metal-Based Drugs that Break the Rules. Dalton Transanction, 45, 3201-3209. https://doi.org/10.1039/C5DT03919C

[4] Ferell, N.P. (2003) Metal Complexes as Drugs and Chemotherapeutic Agents. In: Comprehensive Coordination Chemistry II, Elsevier, Amsterdam, 809-847. https://doi.org/10.1016/B0-08-043748-6/09021-6

[5] Freeman, H.C. (1973) Metal Complexes of Amino Acid and Peptides. In: Eichhorn, G., Ed., Inorganic Biochemistry, Elsevier, United Kingdom, 121-150.

[6] Shivankar, V.S., Vaidya, R.B., Dharwadkar, S.R. and Thakkar, N.V. (2003) Synthesis, Characterization and Biological Activity of Mixed Ligand Complexes of Cobalt(II) Complexes of 8-Hydroxoquinoline and Some Amino Acids. Synthesis and Reactions in Inorganic Metals Organometallic and Nanomaterial Chemistry, 33, 1597-1622. https://doi.org/10.1081/SIM-120025443

[7] Abebe, A. and Hailemariam, T. (2016) Synthesis and Assessment of Antibacterial Activities of Ruthenium(III) Mixed Ligand Complexes Containing 1,10-Phenantroline and Guanide. Bioinorganic Chemistry and Applications, 2016, 1-9. https://doi.org/10.1155/2016/3607924

[8] Krishnanand, M., Himanshu, O. and Nabo, K. (2012) Estimation of Antiradical Properties of Antioxidants Using DPPH Assay: A Critical Review and Results. Food Chemistry, 130, 1036-1043. https://doi.org/10.1016/j.foodchem.2011.07.127

[9] Grune, T., Shringarpure, R., Sitte, N. and Davies, K. (2001) Age-Related Changes in Protein Oxidation and Proteolysis in Mammalian Cells. Journal of Gerontology, 56A, B459-B467. https://doi.org/10.1093/gerona/56.11.B459

[10] Noguchi, N. and Niki, E. (2000) Phenolic Antioxidants: A Rationale for Design and Evaluation of Novel Antioxidant Drug for Atherosclerosis. Free Radical Biology \& Medicine, 28, 1538-1546. https://doi.org/10.1016/S0891-5849(00)00256-2

[11] Saeed, N., Khan, M.R. and Shabbir, M. (2012) Antioxidannt Activity, Total Phenolic and Tot Flavonoid Contents of Whole Plant Extracts. BMC Complementary and Alternative Medicine, 12, 1-12. https://doi.org/10.1186/1472-6882-12-221

[12] Pisoschi, A.M. and Negulescu, G.P. (2011) Methods for Total Antioxidant Activity Determination: A Review. Biochemistry and Analytical Biochemistry, 1, 1-10.

[13] Li, P., Huo, L., Su, W., Lu, R., Deng, C., Liu, L., Deng, Y., Guo, N., Lu, C. and He, C. (2011) Free Radical-Scavenging Capacity, Antioxidant Activity and Phenolic Content of Pouzolzia zeylanica. Journal Serbian Chemistry Society, 76, 709-717. https://doi.org/10.2298/JSC100818063L

[14] Antolovich, M., Prenzier, P., Patsalides, E., McDonald, S. and Robards, K. (2002) 
Methods for Testing Antioxidant Activity. Analyst, 127, 183-198. https://doi.org/10.1039/b009171p

[15] Parsonnet, J. (1995) Bacterial Infection as a Cause of Cancer. Environmental Health Perspectives Supplement, 8, 263-268. https://doi.org/10.1289/ehp.95103s8263

[16] Smith, D.G., Magwere, T. and Burchill, S.A. (2011) Oxidative Stress and Therapeutic Opportunities: Focus on the Ewing's Sarcoma Family of Tumors. Expert Review of Anticancer Theory, 11, 229-249. https://doi.org/10.1586/era.10.224

[17] Prestinaci, F., Pezzotti, P. and Pantosti, A. (2015) Antimicrobial Resistance: A Global Multifaceted Phenomenon. Pathological Global Health, 109, 309-318. https://doi.org/10.1179/2047773215Y.0000000030

[18] Pereira, R., Pereira, A.L., Ferreira, M.M., Fontenelle, R.O.S, Saker-Sampaio, S., Santos, H.S., Bandeira, P., Vasconcelos, M.A., Queiroz, J.A.N., Braz-Filho, R. and Teixeira, E.H. (2019) Evaluation of the Antimicrobial and Antioxidant Activity of 7-Hydroxy-4', 6-Dimethoxy-Isoflavone and Essential Oil from Myroxylon peruiferum Leaf. Annals of the Brazilian Academy of Sciences, 91, 1-13. https://doi.org/10.1590/0001-3765201920180204

[19] Singleton, V.L. and Rossi Jr., J.A. (1965) Colorimetry of Total Phenolics with Phosphomolybdic-Phosphotungstic Acid Reagents. American Journal of Enology and Viticulture, 16, 144-158.

[20] Gulcin, I., Kufrevioglu, O.I., Oktay, M. and Buyukokuroglu, M.E. (2004) Antioxidant, Antimicrobial, Antiulcer and Analgesic Activities of Nettle (Urtica dioica L.). Journal of Ethnopharmacology, 90, 205-215. https://doi.org/10.1016/j.jep.2003.09.028

[21] Brand-Williams, W., Cuvelier, M.E. and Berset, C. (1995) Use of a Free Radical Method to Evaluate Antioxidant Activity. Lebensmittel-Wissenschaft und-Technologie, 28, 25-30. https://doi.org/10.1016/S0023-6438(95)80008-5

[22] Blois, M.S. (1958) Antioxidant Determinations by the Use of a Stable Free Radical. Nature, 29, 1199-1200. https://doi.org/10.1038/1811199a0

[23] Benzie, F.F. and Strain, J.J. (1999) Ferric Reducing/Antioxidant Power Assay: Direct Measure of Total Antioxidant Activity of Biological Fluids and Modified Version for Simultaneous Measurement of Total Antioxidant Power and Ascorbic Acid Concentration. Methods in Enzymology, 299, 15-23. https://doi.org/10.1016/S0076-6879(99)99005-5

[24] Aiyelabola, T.O, Ojo, I.A., Adebajo, C.A., Ogunlusi, G.O., Oyetunji, O. and Akinkunmi, E.O. (2012) Synthesis Characterization and Antimicrobial Activities of Some Metal(II) Amino Acid's Complexes. Advances in Biological Chemistry, 2, 268-273. https://doi.org/10.4236/abc.2012.23034

[25] Pavia, D., Lampman, G. and Kriz, G. (2001) Introduction to Spectroscopy, A Guide for Students of Organic Chemistry. 3rd Edition, Brooks and Cole, New York, 22-368.

[26] Nakamoto, K. (2009) Complexes of Amino Acids. In: Infrared and Raman Spectroscopy of Inorganic Andcoordination Compounds. Applications in Coordination, Organometallics and Bioinorganic Chemistry, 6th Edition, John Wiley and Sons, New York, 67-69.

[27] Greenwood, N.N. and Earnshaw, A. (1997) Coordination Compounds. In: Chemistry of the Elements, 2nd Edition, Oxford, Butterworth-Heinemann, Hong Kong, 1060-1090, $1290-1326$.

[28] Aiyelabola, T.O., Akinkunmi, E., Ojo, I., Obuotor, E., Adebajo, C. and Isabirye, D. (2017) Syntheses, Characterization, Resolution and Biological Studies of Coordination Compounds of Aspartic Acid and Glycine. Bioinorganic Chemistry and Applications, 2017, 1-15. https://doi.org/10.1155/2017/2956145 
[29] Sultana, N., Naz, A., Arayne, M.S. and Mesaik, M.A. (2010) Synthesis, Characterization, Antibacterial, Antifungal and Immunomodulating Activities of Gatifloxacin-Metal Complexes. Journal of Molecular Structure, 969, 17-24. https://doi.org/10.1016/j.molstruc.2010.01.036

[30] Mishra, A., Rathod, J., Namera, D., Thakrar, S. and Shah, A. (2014) Synthesis and Antimicrobial Activity of Coumarinyl Schiff Base Derivatives. International Letters of Chemistry, Physics and Astronomy, 30, 1193-2201. https://doi.org/10.18052/www.scipress.com/ILCPA.30.193

[31] Anacona, J.R. and Lopez, M. (2012) Mixed-Ligand Nickel(II) Complexes Containing Sulfathiazole and Cephalosporin Antibiotics: Synthesis, Characterization, and Antibacterial Activity. International Journal of Inorganic Chemistry, 2012, Article ID: 106187. https://doi.org/10.1155/2012/106187

[32] Kumar, G., Kumar, D., Devi, S., Johari, R. and Singh, C.P. (2010) Synthesis, Spectral Characterization and Antimicrobial Evaluation of Schiff Base $\mathrm{Cu}(\mathrm{II}), \mathrm{Ni}(\mathrm{II})$ and Co(II) Complexes. European Journal of Medicinal Chemistry, 5, 3056-3062. https://doi.org/10.1016/j.ejmech.2010.03.036

[33] Kemp, W. (1991) Infrared Spectroscopy. In: Organic Spectroscopy, Macmillan, Hong Kong, 19-98. https://doi.org/10.1007/978-1-349-15203-2_2

[34] Gómez, V., Vendier, L., Corbella, M. and Costes, J. (2011) Antiferromagnetic Co-Gd Interactions in a Tetranuclear $[\mathrm{CoGd}]_{2}$ Complex with low-Spin Square-Planar Co Ions-Role of the Singly Occupied 3d Co Magnetic Orbital. European Journal of Inorganic Chemistry, 17, 2653-2656. https://doi.org/10.1002/ejic.201100311

[35] Jaynes, B.S., Doerrer, L.H., Liu, S. and Lippard, S. (1995) Stereochemical Tuning of 4-Coordinate Structure Types of Cobalt(II), and the Ground Spin State Consequences of Such Tuning. Journal of Inorganic Chemistry, 34, 5735-5744. https://doi.org/10.1021/ic00127a010

[36] Anitha, C., Sheela, C.D., Tharmaraj, P. and Shanmugakala, R. (2013) Studies on Synthesis and Spectral Characterization of Some Transition Metal Complexes of Azo-Azomethine Derivative of Diaminomaleonitrile. International Journal of Inorganic Chemistry, 2013, Article ID: 436275. https://doi.org/10.1155/2013/436275

[37] Miessler, G.L. and Tarr, D.A. (1999) Coordination Compounds. In: Inorganic Chemistry, Pearson Prentice Hall, New York, 315-316.

[38] Youssef, N.S. and Hegab, K.H. (2005) Synthesis and Characterization of Some Transition Metal Complexes of Thiosemicarbazones Derived from 2-Acetylpyrrole and 2-Acetylfuran. Synthesis and Reactions in Inorganic Metals Organometallic and Nanomaterial Chemistry, 35, 391-399.

https://doi.org/10.1081/SIM-200059215

[39] Raman, N., Pothiraj, K. and Baskaran, T. (2011) Synthesis, Characterization and DNA Damaging of Bivalent Metal Complexes Incorporating Dinitrogen-Dioxygen Ligand as Potential Biocidal Agent. Journal of Coordination, Chemistry, 64, 4286-4300. https://doi.org/10.1080/00958972.2011.638979

[40] Woods, J.A. and Patel, K.S. (1994) Nickel Complexes of Some 3 Substituted-2,4Pentanedione and Their Adducts with 2,2-Bipyridine and 1,10-Phenantroline. Synthesis, Reaction in Inorganic and Organometallic Chemistry, 24, 1557-1571. https://doi.org/10.1080/00945719408002580

[41] Thuery, P. (2013) 2,2-Bipyridine and 1,10-Phenanatroline as Coligands or Structure Directing Agents in Uranyl-Organic Assemblies to Polycarboxylic Acids. European journal of Inorganic Chemistry, 2013, 4563-4573. https://doi.org/10.1002/ejic.201300502 
[42] Meggers, E. (2010) Chiral Auxillaries as Emerging Tools for the Asymmetric Synthesis of Octahedral Complexes. Chemistry: A European Journal, 16, 3. https://doi.org/10.1002/chem.200902652

[43] Prieto, P., Prineda, M. and Anguilar, M. (1999) Spectrophotometric Quantitation of Antioxidant Capacity through the Formation of a Phosphomolybdenum Complex: Specific Application to the Determination of Vitamin E. Analytical Biochemistry, 269, 337-341. https://doi.org/10.1006/abio.1999.4019

[44] Carocho, M. and Ferreira, I.C.F. (2013) A Review on Antioxidants, Proxidants and Related Controversy: Natural and Synthetic Screening and Analysis Methodologies and Future Perspectives. Food and Chemical Toxicology, 51, 15. https://doi.org/10.1016/j.fct.2012.09.021

[45] Holin, R.H., Everett, G.W. and Chakravorty, A. (2009) Metal Complexes of Schiff Bases and Beta Ketoamine. In: Cotton, F.A., Ed., Progress in Inorganic Chemistry, 3rd Edition, Wiley Interscience, New York, 83-214. https://doi.org/10.1002/9780470166086.ch3

[46] Tuncer, S., Koca, A., Gül, A. and Avcrata, U. (2012) Synthesis, Characterization, Electrochemistry and Spectroelectrochemistry of Novel Soluble Porphyrazines Bearing Unsaturated Functional Groups. Dyes and Pigments, 92, 610-618. https://doi.org/10.1016/j.dyepig.2011.05.023

[47] Kostovo, I. (2006) Platinum Complexes as Anticancer Agents. Recent Patents on Anti-Cancer Drug Discovery, 1, 1-22. https://doi.org/10.2174/157489206775246458

[48] Lippert, B. (1999) Cisplatin-Chemistry and Biochemistry of a Leading Anticancer Drug. Verlag Helvetica Chimica Acta, Zürich, and Wiley-VCH, Weinheim, 1-584. https://doi.org/10.1002/9783906390420

[49] Panchal, P.K. and Patel, M.N. (2006) In Vitro Biological Evaluation of Some ONS and NS Donor Schiffs Bases and Their Metal Complexes. Journal of Enzyme Inhibition and Medicinal Chemistry, 21, 453-458. https://doi.org/10.1080/14756360600628551

[50] Nair, S., Arish, O. and Johnson, J. (2016) Synthesis, Characterization and Biological Studies on Some Metal Complexes to Schiff Base Ligand Containing Pyrazolone Moiety. Journal of Saudi Chemical Society, 20, 591-598. https://doi.org/10.1016/j.jscs.2013.04.007 